\title{
LA COMPARACIÓN DE LOS PRONOMBRES DE SEGUNDA PERSONA DEL SINGULAR EN EL ESPAÑOL PENINSULAR Y EN EL EUSKERA: ¿UNA MISIÓN IMPOSIBLE?
}

\author{
Gorka Basterretxea Santiso \\ Universidad de Georgetown (Estados Unidos) \\ gb790@georgetown.edu
}

Recibido: 14/08/2020 - Aprobado: 21/09/2020 - Publicado: 15/04/2021

DOI: doi.org/10.17533/udea.lyl.n79a12

\begin{abstract}
Resumen: Este trabajo toma los pronombres de segunda persona del singular — Pro2s — del español centro-norteño — tú y usted - y del euskera — hi y zu — como base, y con ello revisa estudios empíricos ya publicados sobre el español peninsular (Pedroviejo Esteruelas, 2006; Sampedro Mella, 2016; Sanromán Vilas, 2010). Por su parte, los datos para el euskera se basan en el análisis de 540 conversaciones de la serie Goenkale. Este estudio concluye que los Pro2s no son equivalentes al existir un pronombre pragmáticamente no marcado en euskera: $z u$. La única similitud está entre $u s t e d$ y $z u$ cuando se usan de forma asimétrica.

Palabras clave: español; euskera; pronombres; segunda persona; relaciones interpersonales.

\section{THE COMPARISON OF SECOND PERSON SINGULAR PRONOUNS IN PENINSULAR SPANISH AND IN BASQUE: AN IMPOSSIBLE MISSION?}

\begin{abstract}
This paper takes the second person singular pronouns of North Peninsular Spanish (tú \& usted) and those of Basque $(h i \& z u)$ as the point of departure, and reexamines published empirical studies on northern peninsular Spanish pronouns (Pedroviejo Esteruelas, 2006; Sampedro Mella, 2016; Sanromán Vilas, 2010). The data on Basque pronouns comes from the analysis of 540 conversations from the series Goenkale. This study concludes that the pronouns are not equivalent due to the existence of a pragmatically unmarked pronoun in Basque: $z u$. The only similarity is between usted and $z u$ when they are used asymmetrically.
\end{abstract}

Key words: Spanish; Basque; pronouns; second person; interpersonal relations. 


\section{Introducción}

través del uso de los pronombres de segunda persona del singular — Pro2s - , los hablantes de cualquier 1 lengua crean relaciones interpersonales y sociales con otros hablantes. Este es el caso, por ejemplo, de 1 los Pro2s del español centro-norteño — tú y usted —, así como de los Pro2s del euskera o vasco — hi y $z u$ - Dicho de otra forma, a través del uso simétrico — recíproco: mismos Pro2s entre los hablantes — o asimétrico —no recíproco: uso de diferentes Pro2s entre los hablantes - de estos Pro2s en su correspondiente idioma, los hablantes transmiten un significado pragmático particular hacia los demás participantes en la conversación.

No obstante, estos significados y las relaciones que se crean a través de sus usos han sido diferentes a lo largo de la historia. De hecho, los usos de los Pro2s han evolucionado significativamente. Por ejemplo y para empezar con el español peninsular, en la variedad centro-norteña se ha producido un incremento en el uso de tú, considerado como un pronombre informal (Blas Arroyo, 1995, p. 24; Blas Arroyo, 2005b, p. 302; Carricaburo, 1997, p. 10; De Jonge \& Nieuwenhuijen, 2012, p. 254; León-Castro Gómez, 2014, p. 44). Por su parte, el pronombre que ha visto aumentado su uso en euskera ha sido $z u$, tradicionalmente categorizado como el pronombre formal (Alberdi Larizgoitia, 1995, p. 279; Zubiri \& Zubiri, 2012, p. 118).

Lo anterior puede parecer extraño en un principio debido a que son dos lenguas en constante contacto desde la llegada del latín a la península ibérica ${ }^{1} \mathrm{y}$, por tanto, es posible esperar que ambos idiomas tengan una evolución parecida en este ámbito. Sin embargo, ambas lenguas son tipológicamente distintas y por tanto no es tan sencillo embarcarse en la tarea de equiparar los Pro2s de estas dos lenguas. De este modo, el objetivo de este trabajo es realizar un estudio sincrónico en el que se compara el uso de los Pro2s de las dos lenguas ya mencionadas, además del tipo de relaciones interpersonales que se crean a través de ellos para, así, finalmente, concluir si los Pro2s del español peninsular y del euskera son realmente homologables.

\section{Los pronombres de segunda persona del singular en español y euskera}

Esta sección se divide de la siguiente manera. En primer lugar, se desarrollan los usos de los Pro2s del español centro-norteño para después describir el empleo de los Pro2s del euskera. A continuación, se plantean las preguntas de investigación y las correspondientes hipótesis o predicciones en torno a ellas.

\subsection{El español}

En primer lugar y en referencia a los Pro2s del español peninsular, tradicionalmente se ha utilizado una variedad de conceptos con el fin de definir y diferenciar los usos de tú y usted. Algunos de los más comunes son la dicotomía entre formal e informal (Ardila, 2003, ; Morgan \& Schwenter, 2016; Serrano, 2017) o respetuoso

1. Para más información sobre el contacto entre euskera y español, véase Esparza Celorrio (2006); Fernández Ulloa (2006) y Urrutia Cárdenas (2006). 
La comparación de los pronombres de segunda persona del singular en el español peninsular y en el euskera y descortés o no formal (Carricaburo, 1997; Serrano, 2017), aunque también se defiende que, en realidad, el uso de uno u otro pronombre es la consecuencia de los llamados contratos conversacionales, entendidos como las tradiciones conversacionales propias de cada comunidad de habla (Blas Arroyo, 2005a). Lo cierto es que a cada uno de estos pronombres se le ha asignado un significado pragmático diferente (Lambert \& Tucker, 1976): por un lado, el uso recíproco de tú es normalmente considerado, entre otros, como un caso de solidaridad, familiaridad, confianza, informalidad e igualdad (Blas Arroyo, 2005b; Carricaburo, 1997; de Jonge \& Nieuwenhuijen, 2012). Por otro lado, el uso recíproco de usted es comúnmente comprendido como un caso de distancia emocional y social, deferencia, respeto, formalidad y ausencia de solidaridad (Blas Arroyo, 2005b; Carricaburo, 1997; de Jonge \& Nieuwenhuijen, 2012; León-Castro Gómez, 2014). Estas son las diferencias típicas del español hablado en la región norte de la península ibérica, ya que, por ejemplo, las variedades del español de Andalucía presentan otros usos de los Pro2s (de Jonge \& Nieuwenhuijsen, 2012).

Los significados pragmáticos de estos pronombres varían, además, a la hora de utilizarlos de forma asimétrica o no recíproca. Esto es, si una persona se dirige a su interlocutor con tú, pero este es a su vez tratado de usted, en la mayoría de los casos estará justificado porque el primero tiene un estatus superior al de su interlocutor o porque existe una diferencia de edad entre ambos (Blas Arroyo, 2005b; Carricaburo, 1997; de Jonge \& Nieuwenhuijen, 2012). Además de los significados pragmáticos convencionalmente atribuidos a cada uno de estos pronombres, existen también una serie de causas — como la distancia social, el poder relativo y la solidaridad entre los hablantes - por las que cada emisor elige utilizar uno u otro Pro2s (Blas Arroyo, 1995; Brown \& Gilman, 1960).

En cuanto a la evolución que han sufrido los Pro2s del español peninsular, y tal y como ha sido brevemente mencionado en la introducción de este trabajo, en la actualidad tú también suele utilizarse en aquellos contextos lingüísticos en los que, por ejemplo, entre los años 1960 y 1975, se empleaba el usted (de Jonge \& Nieuwenhuijen, 2012). Una de las posibles causas que justifican este cambio de uso de pronombres en esta zona de la península es la transición a la democracia después de la muerte del dictador Franco en 1975, lo cual trajo más libertad e igualdad al territorio (Ardila, 2003; de Jonge \& Nieuwenhuijen, 2012). Es además considerado un cambio liderado por las generaciones más jóvenes (Calderón Campos \& Medina Morales, 2010; Carricaburo, 1997; de Jonge \& Nieuwenhuijen, 2012).

\subsection{El euskera}

En el caso del euskera, los Pro2s con los que cuenta el idioma son $h i$ y $z u$, aunque cabe destacar que $h i$ no está presente en todas las variedades dialectales del mencionado idioma y que, en la actualidad, la mayoría de los hablantes solo emplea zu (Alberdi Larizgoitia, 1995; Bereziartua Etxeberria \& Muguruza Aseginolaza, 2018). En este caso, y de forma similar a lo descrito anteriormente para el español, una de las dicotomías empleadas para diferenciar los Pro2s del euskera son los conceptos de formal e informal (Saltarelli, 1988) o educado y familiar (de Rijk, 1991, 2008). Normalmente, $z u$ se relaciona con el concepto de respeto, mientras que $h i$ se considera 
La comparación de los pronombres de segunda persona del singular en el español peninsular y en el euskera un pronombre familiar, lo cual podría hacerlos equiparables a los Pro2s del francés vous y tu, respectivamente (Alberdi Larizgoitia, 1995).

Sin embargo, en el caso del euskera, no existe unanimidad entre los estudiosos para utilizar esta diferenciación como caracterización de $h i$ y $z u$, puesto que se defiende que el uso de los conceptos de formal e informal en euskera es el resultado de una comparación equivocada de esta lengua con las lenguas romances (de Rijk, 1991, 2008). Esta es la razón por la cual otros autores ${ }^{2}$ definieron los Pro2s del euskera de la siguiente manera: $h i$ sería el marcador de solidaridad o pronombre íntimo y zu sería un pronombre pragmáticamente no marcado o neutral. Sea cual sea el caso, lo más normal en esta lengua es que — a diferencia de lo que se ha encontrado, por ejemplo, en algunas variedades del español, como el chileno ${ }^{3}$ - los interlocutores nunca varíen el uso de estos Pro2s para referirse a una persona en concreto a lo largo de los años, aunque es cierto que existe cierta posibilidad de cambio (Alberdi Larizgoitia, 1994).

En el caso del euskera es destacable además que estos Pro2s estén regidos por una serie de restricciones especialmente concretas. Estas reglas indican que, por ejemplo, es más común utilizar el pronombre $h i$ solo entre amigos que sean del mismo sexo — sobre todo entre hombres_-, entre hermanos, por parte del padre hacia el hijo — nunca se da el caso contrario — , entre personas que pertenezcan a clases sociales similares, y para hacer referencia a interlocutores de un nivel social más bajo (Alberdi Larizgoitia, 1991, 1994, , 1995,; Amorrortu, 2003; de Rijk, 1991; Bereziartua Etxeberria \& Muguruza Aseginolaza, 2018; Euskaltzaindia, 2002; Trask, 2003). En cambio, entre las parejas casadas, lo más común es el uso simétrico de zu (Bereziartua Etxeberria \& Muguruza Aseginolaza, 2018).

$Z u$ es el que se usa en la mayoría de las interacciones y puede ser considerado como el registro estándar, mientras que $h i$ pertenece al registro familiar en aquellos dialectos en los que se da su uso (Wolpert et al., 2017). Además, en esos dialectos del euskera en los que se frecuenta el uso de $h i$, la asimetría en cuanto al uso de los Pro2s es más frecuente - sobre todo en el ámbito familiar — que en el español y el francés (Alberdi Larizgoitia, 1991, , 1994). En cambio, las restricciones para el uso de $z u$ son más simples en comparación con hi: se acepta su uso en todos aquellos casos en los que no se pueda emplear $h i$, y en cualquier contexto conversacional en aquellas variedades del euskera en las que no se produzca $h i$.

La historia de estos Pro2s demuestra que los contextos en los que se emplean no han evolucionado mucho en los últimos 500 años (Alberdi Larizgoitia, 1995), pero la frecuencia de uso se ha visto muy afectada, sobre todo en detrimento de hi (Alberdi Larizgoitia, 1995; Euskaltzaindia, 1991; Saltarelli, 1988; Zubiri \& Zubiri, 2012). Cabe destacar también que el uso de hi es más frecuente entre hombres que entre mujeres (Amorrortu, 2003; Bereziartua Etxeberria \& Muguruza Aseginolaza, 2018; Wolpert, Mancini \& Caffarra, 2017). En el siglo pasado, autores como de Rijk (1991) y Saltarelli (1988) ya mencionaban la posible pérdida de la distinción entre los Pro2s, además de que el uso de $h i$ estaba siendo relegado - con alguna excepción — principalmente a dialectos

\footnotetext{
2. Véase Amorrortu (2003) y de Rijk (1991, 2008).

3. Véase Fernández Mallat (2020).
} 
La comparación de los pronombres de segunda persona del singular en el español peninsular y en el euskera de zonas rurales. Las causas comúnmente mencionadas para justificar este descenso de uso son, entre otras, i) la abundante morfología en la formación verbal que lo acompaña comparado con la morfología de $z u$, ii) el mal nombre y las connotaciones negativas ${ }^{4}$ que se le han atribuido en algunas zonas del País Vasco, lo que dificulta la transmisión de padres a hijos de este pronombre; y iii) el escaso número de trabajos literarios antiguos en los que se ve reflejado el uso de este pronombre por haberse tratado menos el género del teatro en el que se recoge un registro más informal (Alberdi Larizgoitia, 1991, 1995). No obstante, aunque es evidente que en algunas zonas hi recibió connotaciones peyorativas, en la actualidad, en cierta medida, se ha revitalizado su uso (de Rijk, 1991, 2008; Euskaltzaindia, 1991; Zubiri \& Zubiri, 2012).

El cambio principal o más radical de los Pro2s de esta lengua está relacionado con zu. Ya se ha mencionado que hoy en día este es un pronombre de segunda persona del singular, pero no era así en su origen. Inicialmente, $z u$ era el pronombre de segunda persona del plural y, por tanto, $h i$ era el único pronombre que existía en la segunda persona del singular (Alberdi Larizgoitia, 1995; Amorrortu, 2003; de Rijk, 2008; Euskaltzaindia, 1991, 2002; Trask, 1997, 2003; Zubiri \& Zubiri, 2012). Sin embargo, se cree que zu pasó a formar parte del grupo de los Pro2s probablemente como consecuencia del contacto del euskera con las lenguas romances - en este caso el español y el francés - y fue considerado como pronombre formal (Alberdi Larizgoitia, 1995; Zubiri \& Zubiri, 2012). Así, el lugar de $z u$ fue ocupado por el pronombre plural de segunda persona que se usa en la actualidad: zuek (Alberdi Larizgoitia, 1995; de Rijk, 1991, 2008; Zubiri \& Zubiri, 2012). Por su parte, zu siguió su propia evolución y, con el paso del tiempo, ha llegado a ocupar todos los contextos conversacionales posibles (Zubiri \& Zubiri, 2012). Por esta razón, podría no ser solo un pronombre formal y esta es una de las razones por las cuales otros autores 5 defienden que, en realidad, $z u$ se convirtió en el pronombre pragmáticamente no marcado o neutral del euskera mientras que $h i$ vio disminuido su uso.

Cabe destacar que, en euskera, además de los Pro2s anteriormente descritos, hay otros Pro2s, aunque su uso no sea tan común. Este es el caso de berori, un pronombre derivado del pronombre demostrativo hori «ese», cuyo uso en la actualidad es tan limitado — incluso a veces considerado en desuso- que únicamente suele emplearse, por ejemplo, en peticiones formales escritas (de Rijk, 1991, 2008; Euskaltzaindia, 1991, 2002; Saltarelli, 1988; Trask, 1997, 2003; Zubiri \& Zubiri, 2012). Sin embargo, antes de que zu acaparara también los contextos de uso de este pronombre, berori solía ser empleado por parte de los agricultores para referirse a sacerdotes, monjes, doctores, y personas de rango similar (de Rijk, 1991, 2008). Berori es un pronombre formal que, aunque formalmente se conjugue en tercera persona del singular, su significado suele ser atribuido a la segunda persona del singular (Alberdi Larizgoitia, 1995; de Rijk, 2008; Euskaltzaindia, 1991, 2002; Zubiri \& Zubiri, 2012). Por último, esta lengua también cuenta con la presencia de otro pronombre de segunda persona del singular: $x u$. Este particular pronombre se produce únicamente en los dialectos del este y es el resultado de la palatalización de $z u$ (Alberdi Larizgoitia, 1995; Amorrortu, 2003; Trask, 1997, 2003). Además, su significado en cuanto a intimidad está entre

4. Algunos vascos han relacionado el uso de hi de forma negativa con la idea de un euskera robusto, fuerte y feo (Alberdi, 1991).

5. Véase Amorrortu (2003); de Rijk (1991, 2008). 
La comparación de los pronombres de segunda persona del singular en el español peninsular y en el euskera los de hi y zu (Trask, 1997, 2003).

Así, y volviendo a los usos y significados de los Pro2s de las dos lenguas con el fin de establecer una comparación entre ambas, ya hay autores que mencionan que tú no es equiparable a $h i$, y que $z u$ tampoco es equiparable a usted (Alberdi Larizgoitia, 1996; Echeverria, 2003; Larramendi, 1728, 1729). De hecho, se ha defendido que el significado de $z u$ estaría entre aquellos de tú y usted (Alberdi Larizgoitia, 1996). Sin embargo, estas afirmaciones no son actuales y tampoco están basadas en estudios empíricos, son solo generalizaciones y sugerencias.

Con todo lo anterior, el presente trabajo plantea un estudio sincrónico que busca ser el inicio de la comparación de Pro2s entre dos lenguas vecinas, que, sin embargo, no pertenecen a la misma familia lingüística. En él se compara el uso de los Pro2s del español centro-norteño de la península ibérica y del euskera. La innovación propuesta para el trabajo es el análisis empírico de esta segunda lengua, además de las conclusiones que se extraerán acerca de la posibilidad o imposibilidad de comparación entre ambas lenguas. De esta forma, y teniendo en cuenta lo expuesto anteriormente, se plantean dos preguntas de investigación generales para el desarrollo de este estudio:

1. ¿En qué contextos se usan los Pro2s propios de cada lengua, en el español centro-norteño y en euskera?

2. De acuerdo con los usos descritos en la pregunta anterior, ¿los Pro2s correspondientes son equiparables $t u=h i$ y $u s t e d=z u$ - entre los dos idiomas?

Por su parte, y basándonos en lo que la literatura previa ha declarado, tal y como ha sido introducido en esta sección, las siguientes son las predicciones sobre las que se trabaja en este proyecto:

1. En el caso del español, es evidente el aumento en la frecuencia de uso de tú en detrimento de usted y, en consecuencia, se anticipa que todas las conversaciones estarán regidas por tú, a excepción de algunas conversaciones minoritarias en las que haya distancia social y relaciones de poder entre los interlocutores. En cuanto al euskera, se anticipa que en la mayoría de las conversaciones habrá un uso recíproco de $z u$. Además, se espera que los usos de los Pro2s sigan todas las reglas establecidas en el euskera presentadas anteriormente.

2. Se espera que los Pro2s de las dos lenguas analizadas no sean equiparables, particularmente, por el uso complejo de los Pro2s del euskera y de los amplios significados y relaciones interpersonales que se pueden establecer a través de ellos, además de la existencia de un posible pronombre pragmáticamente no marcado en euskera $-z u-$.

\section{Metodología}

La metodología diseñada para la comparación propuesta en este estudio está dividida en dos y se basa en una perspectiva cualitativa: una para el análisis del español y otra para el del euskera. En cuanto al español peninsular, se han revisado algunas publicaciones anteriores centradas en el español centro-norteño. En efecto, los estudios empíricos analizados en este artículo son los siguientes: Pedroviejo Esteruelas (2006) con una encuesta a 28 jóvenes hablantes del español de Valladolid, Sampedro Mella (2016) con resultados de encuestas de uso, 
La comparación de los pronombres de segunda persona del singular en el español peninsular y en el euskera encuestas de creencias y corpus orales acerca del uso de los Pro2s en el español centro-norteño, y Sanromán Vilas (2010), con encuestas sobre los Pro2s a 288 personas de Vigo y Madrid. La razón por la cual se ha optado por observar estos trabajos en lugar de la recogida de datos es que en el español centro-norteño no se observa un cambio significativo en el uso de los Pro2s en los últimos años. De igual manera, son estudios relativamente recientes, y en los tres se observan resultados que siguen el mismo patrón, lo cual permite describir así el uso de los Pro2s en el español centro-norteño. Así pues,ara el presente estudio, se han observado los resultados de dichas investigaciones y se han creado patrones generales extraídos de ellas.

Por su parte, para el análisis de los Pro2s en euskera se creó una base de datos con un total de 540 conversaciones extraídas de la serie Goenkale, perteneciente a Euskal Irrati Telebista — la televisión pública vasca- En estas conversaciones participaron un total de 35 personajes de la serie que representan todo tipo de edades y se dividen en 20 mujeres y 15 hombres. Más concretamente, el total de conversaciones que forman parte de la base de datos datan del año 2008 y de los 60 episodios que fueron emitidos durante el mencionado año. Esta base de datos está formada por las transcripciones de los diálogos producidos entre los personajes de la serie, obtenidos a través del corpus Lexikoaren Behatokiaren Corpusa «Corpus del Observatorio Léxico», y traducidos al español por el autor de este artículo. La serie se sitúa en una localidad ficticia, Arralde, en la provincia de Gipuzkoa, y presenta una variedad en la que algunos de los personajes incluyen el uso de $h i$ además de $z u$.

Aunque es evidente que los diálogos de una serie de televisión son preparados con antelación por un equipo de guionistas y, por tanto, no pueden ser considerados como lenguaje natural (Nuzzo, 2015), lo cierto es que autores como Quaglio (2009) han defendido que las conversaciones emitidas a través de la televisión se acercan mucho al habla verdadera, con el objetivo de que los espectadores se sientan identificados con esas formas de hablar.

En el caso del presente análisis, se identificaron tanto los pronombres explícitos como los omitidos, gracias a la morfología verbal que no da lugar a equívocos en las conversaciones - tanto en euskera como en español se pueden omitir los sujetos - para así tener acceso a más muestras.

En cuanto a la codificación de los resultados de ambas lenguas, el análisis se divide en tres tipos de relaciones entre los interlocutores, considerados como variables independientes: familia, amistad y distancia social o de poder. Dentro de estas variables también se consideran características como la edad y el género. Se eligieron estas variantes para el presente estudio, dado queel género, la edad y la cercanía con las personas son las variables que más rigen los usos de los Pro2s, por lo menos en el caso del euskera (Bereziartua Etxeberria \& Muguruza Aseginolaza, 2018). Además, se sigue la definición de cortesía propuesta por Brown y Levinson $(1978,1987)$ para analizar la creación de relaciones interpersonales: la cortesía implica que puede producirse una ofensa o agresión verbal hacia una persona, y su objetivo es apaciguar esa posibilidad para dar paso a una comunicación cordial. 
La comparación de los pronombres de segunda persona del singular en el español peninsular y en el euskera

\section{Resultados}

\subsection{El español}

Para contestar a la primera parte de la primera pregunta de investigación de este proyecto, que hace referencia a los contextos en los que se utiliza cada uno de los Pro2s del español centro-norteño de la península ibérica, el análisis de los tres estudios ya introducidos (Pedroviejo Esteruelas, 2006; Sampedro Mella, 2016; Sanromán Vilas, 2010) indica que la predicción planteada - uso mayoritario de tú en todas las conversaciones- en este trabajo se confirma para los tres tipos de relación analizados.

En cuanto a las relaciones familiares, estos estudios demuestran que sea cual sea el tipo de relación familiar, estas conversaciones están guiadas por tú. Por ejemplo, los tres trabajos citados encontraron que entre las parejas las conversaciones están dominadas por el uso recíproco de tú, al tratarse de una relación estrecha, íntima y entre iguales. En otro ejemplo, Sanromán Vilas (2010) reveló que la situación entre hermanos es similar a la de las parejas. No obstante, es interesante que también se obtuvieran resultados que indican que es evidente el cambio de uso de los Pro2s a lo largo del tiempo a la hora de referirse a personas mayores — padres, abuelos, suegros, tíos, entre otros - por parte de jóvenes: encontró casos que indicaban que aquellos que nacieron entre 1910 y 1929 utilizaban usted a diferencia de los nacidos más recientemente.

Frente a las conversaciones entre amigos, los resultados de los tres autores examinados indican que lo más común en estas interacciones, de nuevo, es utilizar tú de forma simétrica. De hecho, según Sanromán Vilas (2010) este sería el único pronombre empleado sin importar la generación de los hablantes, situación poco extraña si se considera que la amistad suele estar regida por el conocimiento, la familiaridad y la igualdad. No obstante, Sampedro Mella (2016) y Sanromán Vilas (2010) descubrieron que cuando la amistad se produce entre personas que pertenecen a diferentes generaciones, aparece el uso no recíproco de usted: los jóvenes se dirigen a sus amigos mayores con usted,mientras que los mayores emplean tú para referirse a los más jóvenes. Sin embargo, cabe destacar que, de acuerdo con Sanromán Vilas (2010), ha habido un cambio generacional al respecto, pues parece que el uso asimétrico de los Pro2s se produce únicamente entre aquellas personas que nacieron antes de la década de 1970.

Finalmente, al revisar los resultados de las conversaciones en las que hay diferencia de poder y de nivel social, se halla que los resultados no son tan claros y unificados como en los contextos anteriormente mencionados. Además, los tres estudios analizados en este artículo observaron que este es el contexto en el que más se presenta el uso asimétrico de los Pro2s en la actualidad. Por ejemplo, Sampedro Mella (2016) descubrió que en estos casos sigue habiendo una gran posibilidad de que en las conversaciones la persona con poder o un estatus social superior se dirija a su interlocutor con tú, mientras que recibe un trato de usted. De todas formas, Sanromán Vilas (2010) reveló que también parece haber un cambio generacional: el uso de usted era mayor entre los hablantes que habían nacido antes de la década de 1980, comparado con los nacidos después. Por su parte, Pedroviejo Esteruelas (2006) 
La comparación de los pronombres de segunda persona del singular en el español peninsular y en el euskera especificó tres contextos diferentes con distancia de poder: el primero se sitúa en las universidades, donde los alumnos usan más usted para dirigirse al profesorado, aunque la elección del pronombre depende de la cercanía y accesibilidad de cada instructor; el segundo se da con los trabajadores de un banco, con los que se descubrió que los clientes usaban más usted que tú; y finalmente en el contexto de un bar, donde los clientes más jóvenes se inclinaban a usar el pronombre tú para hablar con los camareros de una generación similar, mientras que el uso de usted era mayor para hacer referencia a aquellos camareros que pudieran tener más de 40 años.

\subsection{El euskera}

Tal y como ha quedado evidenciado en la segunda sección de este trabajo, en la que se ha repasado la literatura previa, el uso de los Pro2s de euskera es más complejo que el del español centro-norteño en la península ibérica. Además, hay que recordar que en los diálogos de Goenkale analizados en este artículo se puede usar tanto hi como $z u$, lo cual no significa que todos los personajes empleen ambos pronombres. En este caso, también, la predicción inicial sobre la que se trabajaba — el uso recíproco de zu será mayoritario y los personajes respetarán las normas de uso de los Pro2s - queda confirmada.

En las conversaciones producidas en el contexto familiar, lo primero que se ha observado en la mencionada serie es que ninguna mujer joven emplea el pronombre $h i$, lo cual era de esperarse, ya que autores como Amorrortu (2003) han sostenido que el uso de este pronombre entre mujeres es muy limitado. En cuanto a los hombres jóvenes, sí se ha observado el uso de $h i$, además de forma recíproca, solamente entre hermanos, como en el extracto $(1)^{6}$, creando así una relación cercana e igualitaria.
Kandido
Kanposantura joateko gai ez eta tabernan geratu ninduan. Andoni iritsi zuan orduan. Handik gutxira hi, eta gero bera. Dios!
No fui capaz de ir al cementerio y me quedé en el bar. Entonces llegó Andoni. Al poco tiempo tú, y después él. ¡Dios!
German Etzak hire burua gehiago estutu.
No te tortures más a ti mismo.
Kandido Hilartean neurekin eramango diat oinaze hori. Badakik? Kanposantura joan nahi nian gaur... Olga ikustera. Baina ez diat kemenik izan. Llevaré este mal conmigo hasta que me muera. ¿Lo sabes? Hoy quería ir al cementerio... a ver a Olga. Pero no he tenido fuerzas.
German Hago lasai. Ahaztu egin behar duk dena. Estate tranquilo. Tienes que olvidarlo todo.
Kandido Minak ez zidak uzten.
El dolor no me deja.
German Saiatu egin behar duk. Olgak ere horixe nahiko zian: hik gehiago ez sufritzea. Hik ba al hekien Bogarena?
Tienes que intentarlo. Olga también querría eso: que tú no sufrieras más. ¿Tú sabías lo de Boga?

\footnotetext{
6. En todos los extractos conversacionales se han subrayado en euskera los elementos a través de los cuales se deduce el uso de
} hi $\mathrm{o} z u$. 
La comparación de los pronombres de segunda persona del singular en el español peninsular y en el euskera

Kandido

Ez. Aliziaren kontua izan duk.

No. Ha sido cosa de Alizia.

Sin embargo, tal y como se ha mencionado en el párrafo anterior, el uso simétrico de $h i$ solo se produce entre hermanos, ya que cuando existe otro tipo de relación, sobre todo marcada por una diferencia generacional, el uso de los Pro2s no es recíproco. A modo de ejemplo, se ofrece la conversación (2) entre un padre y un hijo, en la que el padre — Abel — se dirige al hijo con hi y el hijo — German — le habla al padre con zu. De forma similar, se observa el mismo patrón, como en el caso de un abuelo y su nieto. La diferencia de edad, además, afecta a ambos géneros de los hablantes, aunque los casos de asimetría entre una mujer y un hombre, como se muestra en (3), donde Abel es el abuelo y Joana la nieta, son más escasos.

(2)

Abel Eta hik, zer egiten duk hemen? Y tú, ¿qué haces aquí?

German Ez... Egia esan, zu hemen ikusi zaitudanetik, gauza bakarra daukat buruan... Zer moduz doa Aketzarena?

No... A decir verdad, desde que te he visto aquí, solo tengo una cosa en la cabeza... ¿Cómo va lo de Aketza?

Abel Utzidak niri. Hik zenbat eta gutxiago jakin, hobe niretzat. Déjamelo a mí. Cuanto menos sepas tú, mejor para ti.

German $\quad$ Zukala badiozu...

Si tú lo dices...

Abel Korapiloa konponduko nuela agindu nian, ezta? Kito ba. Hala ere, datu gehiago eman beharko dizkidak.

Te prometí que arreglaría el lío, ¿verdad? Pues ya está. Aun así, me tendrás que dar más datos.

German Ados, baina arazoak ditut merkantziaren zain daudenekin.

De acuerdo, pero tengo problemas con los que están esperando la mercancía.

(3)
Abel
Arratsalde on.
Buenas tardes.
Joana
Aitona! Zer moduz?
¡Abuelo! ¿Qué tal está (usted)?
Abel
Hi hobeto. Pozik ikusten haut.
Tú mejor. Te veo contenta.
Joana
Bai. Zatoz, lagun bat aurkeztuko dizut.

Sí. Venga, le voy a presentar a un amigo.

El resto de las conversaciones familiares están marcadas por el uso simétrico de $z u$, tal y como se mencionó y se ilustra en (4), que consiste en una conversación entre dos hermanas. Es destacable que entre algunos hablantes familiares se ha encontrado el uso recíproco de $z u$, cuando lo esperado era un uso asimétrico, por ejemplo, entre padres e hijos, porque los personajes del caso (5) utilizan hi en otros ámbitos conversacionales. Esto es lo que ocurre en la conversación (5) entre un padre (Unai) y su hijo (Lukas). 
La comparación de los pronombres de segunda persona del singular en el español peninsular y en el euskera

(4)

Ikerne Eta zuk zer egiten duzu hemen? Hau nire gela da! Ospa!

¿Y tú qué haces aquí? ¡Esta es mi habitación! ¡Vete!

Naia Argazki albumak hemen daude eta... Barkatu.

Los álbumes de fotos están aquí y... Perdona.

Ikerne $\quad$ Ez, ez... Barkatu zuk. Ez da zure errua.

No, no, perdóname tú. No es tu culpa.

Naia Baina haserre zaude.

Pero estás enfadada.

Ikerne Bai, Joana alu horrek kabreatu egiten nau!

¡Sí, la canalla esa de Joana me ha enfadado!

Naia Ezin da hori esan! Amak ez du uzten!

¡No se puede decir eso! ¡Mamá no deja!

Ikerne Egia ... ez esan amari. Bale? Zer argazki ari zara ikusten?

Cierto... no se lo digas a mamá. ¿Vale? ¿Qué foto estás viendo?

Naia Aspaldikoak! Begira hau. Ama eta... aita dira, ez?

¡De hace tiempo! Mira esta. Son mamá y... papá, ¿no?

Ikerne Bai, oso pozik daude hemen.

Sí, aquí salen muy contentos.

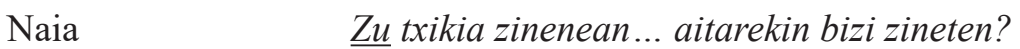

¿Cuando tú eras pequeña... vivíais con papá?

Ikerne Jakina!

¡Por supuesto!

(5)

Lukas

Unai! Iritsi zara! Lastima... Hemendik aurrera komuna konpartitu beharko dugu.

¡Unai! ¡Has llegado! Pena... A partir de aquí vamos a tener que compartir el baño.

Unai Neuk ere maite zaitut! Etorri hona.

¡Yo también te quiero! Ven aquí.

(Elkar besarkatzaen dute biek, elkarri bizkarrean kolpe abegitsuak emanez).

(Ambos se dan un abrazo, dando palmadas acogedoras en la espalda del otro).

Unai Beti bezain itsusi zaude!

¡Estás tan feo como siempre!

Lukas Eta zu gizenduta!

¡Y tú has engordado!

Unai Faltan bota zaitut!

¡Te he echado de menos!

Lukas Ba nikez. Alde ederreko bakea zu gabe!

Pues yo no. ¡Vaya paz sin ti!

(Irri egiten dute biek).

(Ambos se ríen).

También dentro del ámbito familiar, en lo que respecta a las interacciones dentro de la pareja, se ha encontrado solo el empleo simétrico de $z u$, como en (6), sin que importe la edad, el género, la duración de la relación, o la 
La comparación de los pronombres de segunda persona del singular en el español peninsular y en el euskera condición sexual, a excepción de una pareja homosexual masculina que empleó $h i$ de manera simétrica, tal y como se puede comprobar en (7). Es posible que en estos casos $z u$ tenga un uso similar al que se tiene de usted en algunos países como Costa Rica y Colombia, donde puede ser utilizado de manera formal pero también de forma íntima (Calderón Campos, 2010).

(6)

Leonor Naroak afaltzera gonbidatu nau. Nekane, Mimi, bera eta ni. Naroa me ha invitado a cenar. Nekane, Mimi, ella y yo.

Koldo Eta ahaztu egin zaizu!

¡Y se te ha olvidado!

Leonor Bai, oraintxe deituko diot ez noala esateko.

Sí, le voy a llamar ahora para decirle que no voy.

Koldo Itxoin... zoaz afaltzera!

¡Espera... vete a cenar!

Leonor Ezetz, Koldo. Lehenbailehen oheratu eta zuri besarkatuta egon nahi dut, ulertzen?

Que no, Koldo. Quiero acostarme cuanto antes y estar abrazada a ti, ¿entiendes?

Koldo Entzuidazu, Atxurin Nekanerekin egin dut topo eta zerbait ezkutatzen dugula igarri didala uste dut.

Escúchame, me he encontrado a Nekane en Atxuri y creo que me ha notado que escondemos algo.

Leonor $\quad$ Ai, virgencita...

Ai, virgencita...

Koldo Zoaz afari horretara eta ahalik eta alaien egoten saiatu.

Vete a esa cena e intenta estar lo más contenta posible.

Leonor Ok! Ok. Ronzito bat hartuko dut eta inork ez dit ezer antzemango.

Ok! Ok. Me tomaré un roncito y nadie me notará nada.

Koldo Zoaz eta saiatu ondo pasatzen.

Ve e intenta pasarlo bien.

Leonor Eta zuk zer egin behar duzu hemen bakarrik?

¿Y tú qué vas a hacer aquí solo?

Koldo Niregatik ez arduratu. Ohera joango naiz. Gaurko eguna ahaztu egin nahi dut.

No te preocupes por mí. Iré a la cama. Quiero olvidar el día de hoy.

Leonor Bihar ere egunak argituko du, mi amol. Diru hori lortuko dugu. Egongo da moduren bat.

Mañana también amanecerá, mi amol. Conseguiremos ese dinero. Habrá algún momento.

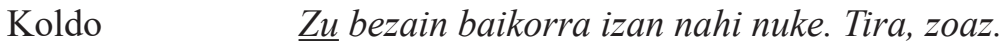

Me gustaría ser tan positivo como tú. Anda, vete.

Leonor Zerbait jantzi eta banoa!

¡Me pongo algo y me voy!

(7)

Alex Bueno, hasi heu.

Bueno, empieza tú. 
La comparación de los pronombres de segunda persona del singular en el español peninsular y en el euskera

$\begin{array}{ll}\text { Markel } & \text { Ez, heu aurrena. } \\ & \text { No, tú primero. } \\ \text { Alex } & \text { Hi agertu haiz hotelean ezustean. } \\ & \text { Has aparecido tú en el hotel por sorpresa. } \\ \text { Markel } & \text { Ja, baina hik ere gauza garrantzitsuren bat esan behar didak, ezta? } \\ & \text { Ya, pero tú también me tienes que decir algo importante, iverdad? } \\ \text { Alex } & \text { iVaya lío! } \\ \text { Markel } & \text { Hasi orduan askatzen. } \\ & \text { Entonces empieza a soltarlo. } \\ \text { Alex } & \text { Konforme, neu hasiko nauk. } \\ & \text { De acuerdo, empezaré yo. }\end{array}$

Ahora bien, en el caso de las conversaciones producidas entre amigos, se ha notado el uso simétrico de $h i$ solo entre personas que pertenecen a la misma generación, sin importar el género de los participantes. Esto queda ilustrado en (8) con una conversación entre dos hombres jóvenes, y en (9) entre una mujer y un hombre jóvenes, Rakel y Kevin.

Lukas Orduan animatzen haiz?

Kevin Ezin diat, berehala itzuli behar diat hotelera. Erreminta batzuen bila atera nauk.

No puedo, tengo que volver enseguida al hotel. He salido a buscar algunas herramientas.

Lukas Hi bai koldarra.

Tú eres un cobarde.

Kevin Zer?

¿Qué?

Lukas Tipo ausarta hintzela uste nian. Tipo... arriskutsua.

Creía que eras una persona valiente. Un tipo... peligroso.

Kevin Ez adarrik jo, txikito. Gorriak pasatu dizkiat nik. Hik, berriz, ez dakik zer den kaleko gordina, pijo hutsa haiz.

No me tomes el pelo, chaval. Yo lo he pasado muy mal. Tú, en cambio, no sabes lo que es la dureza de la calle, eres un pijo.

(9)

Rakel

Zer daukak? Kontaidak, mesedez.

¿Qué te pasa? Cuéntamelo, por favor.

Kevin Oker hago, Rakel, ez dun hik pentsatzen duana, baina ezin dinat ezer esan.

Estás equivocada, Rakel, no es lo que tú te piensas, pero no te puedo decir nada.

Rakel Lagunakgaituk, Kevin, eta elkarri laguntzeko gaudek. Nik gaizki pasatu nuenean, hik lagundu hidan; orain utzidak niri.

Somos amigos, Kevin, y estamos para ayudarnos el uno al otro. Cuando yo lo pasé mal, tú me ayudaste; ahora déjame a mí. 
La comparación de los pronombres de segunda persona del singular en el español peninsular y en el euskera

Kevin Baserriko sutean han nengonan ..., gizon hura hil zunan sutean. Begira

(zauria erakusten dio). Eta ez naun medikuarengana joan ...

Estaba en el incendio del caserío..., en el incendio en el que se murió

aquel hombre. Mira (le enseña la herida). Y no he ido al médico...

Aun así, y como se predijo, el número de uso de hi recíproco entre mujeres jóvenes de la misma generación es mucho menor que entre los hombres jóvenes de la misma generación, apoyando así el hecho de que los hombres jóvenes emplean más este pronombre que las mujeres (Amorrortu, 2003). Es por eso que el uso simétrico de $z u$ entre mujeres jóvenes es mucho más común, como en (10). Esto puede confirmar la tendencia que se observa en estudios sociolingüísticos, en la cual las mujeres son frecuentemente quienes usan la variante más innovadora. Este es un resultado totalmente distinto del de las conversaciones entre hombres jóvenes al no encontrar ni un solo caso de uso recíproco de $z u$.

(10)

\begin{tabular}{|c|c|}
\hline Naroa & $\begin{array}{l}\text { Hara, Nekane! Zer, galduta? } \\
\text { ¡Mira, Nekane! ¿Qué, perdida? }\end{array}$ \\
\hline Nekane & $\begin{array}{l}\text { Haize apur bat behar nuen. Ito beharrean nengoen eta. Eta zu, zelan ba } \\
\text { hemen? } \\
\text { Necesitaba un poco de aire. Estaba ahogándome. ¿Y tú, qué haces aquí? }\end{array}$ \\
\hline Naroa & $\begin{array}{l}\text { Lanean. Beste bezero bat lortu dut, eta pozik. } \\
\text { Trabajando. He conseguido otro cliente, y contenta. }\end{array}$ \\
\hline Nekane & $\begin{array}{l}\text { Zorionekoa zu! Ni nazka-nazka eginda nago nire behar madarikatuarekin. } \\
\text { ¡Qué suerte tienes! Yo estoy cansadísima con mi maldito trabajo. }\end{array}$ \\
\hline Naroa & $\begin{array}{l}\text { Bai zera! Zuk atsegin duzu zure lana. } \\
\text { ¡Qué dices! A ti te gusta tu trabajo. }\end{array}$ \\
\hline Nekane & $\begin{array}{l}\text { Ez dizut esango ezetzik, baina azken boladan komisarian sartu orduko, beti } \\
\text { daukat norbait errieta egiteko zain. } \\
\text { No te diré que no, pero últimamente al entrar en la comisaría, siempre tengo } \\
\text { a alguien esperándome para echarme la bronca. }\end{array}$ \\
\hline
\end{tabular}

A pesar de todo, también se han encontrado escasos casos en los que dos amigos del mismo sexo usan los Pro2s de manera asimétrica, como se muestra en el extracto (11). La principal razón por la cual los hablantes de la conversación (11) no usan los pronombres de forma simétrica es la diferencia de edad que existe entre los dos: Abel es la persona mayor y es por eso que se dirige a Andoni, el más joven, con $h i$, mientras que Andoni se refiere a Abel con $z u$.

(11)

Andoni Hildakoa kaleko eskaleren bat zelakoan gaude.

Creemos que el muerto era un mendigo.

Abel Bai. Holako tokietan bilatzen dik babesa jende horrek. Goxo egoteko sua piztu eta akabo!

Sí. Esa gente encuentra refugio en sitios como ese. ¡Encender el fuego para estar calentito y ya está!

Andoni Ez zabiltza oker. Hori da esku artean daukagun hipotesia.

No va por mal camino. Esa es la hipótesis que tenemos entre manos. 
La comparación de los pronombres de segunda persona del singular en el español peninsular y en el euskera
Abel
Gogoan diat antzeko kasu bat. Aramaion gertatu zuan.
Andoni $\quad$ Era guztietako kasuak ikertu dituzu ezta?
Me recuerda a un caso parecido. Ocurrió en Aramaio.
Abel Zer nahi duk? Maite diat lanbide hau eta onena eman zioat.
¿Qué quieres? Amo este trabajo y le doy lo mejor.
Andoni
Zuk dakizunaren erdia jakingo bagenu!
Abel Tira, tira, ez duk horrenbesterako ere. Lortu duk Nekanerekin hitz egitea?
Bueno, bueno, tampoco es para tanto. ¿Has conseguido hablar con Nekane?
Andoni Ez. Lanpetuta dabil Milenaren kasuarekin eta kontatuko diot itzultzen denean.
No. Está ocupada con el caso de Milena y se lo diré cuando vuelva.
Abel
Bistan zagok. Azkenean heure esku zagok kasua. Andoni, hik ez duk
Nekane leku txarrean utzi nahi, baina hemen norberak irabazten dik bere fama.
Está claro. Al final el caso está en tus manos. Andoni, tú no quieres dejar en mal lugar a Nekane, pero aquí cada uno tiene su fama.
Andoni
Nekane oso buruzagi ona da.
Nekane es muy buena jefa.
Abel Hala izango duk. Baina lehen ere esan nian, emakume hori ez duk egokia kasua eramateko. Lotura handiegia zaukak umearekin.
Así será. Pero ya te lo dije antes, esa mujer no es la adecuada para llevar el caso. Tiene demasiada relación con la niña.

En cuanto a las interacciones marcadas por una relación de distancia social y poder, se ha encontrado que todos los hablantes hacen uso del pronombre $z u$ de manera simétrica, tal y como es el caso de (12), una conversación entre una camarera - Margari-y su jefa —Alizia—; y en (13) entre una empleada —Enriketa — y su jefe - German- No obstante, cabe mencionar que también se han encontrado dos conversaciones en las que se presenta un uso asimétrico de los Pro2s, ambas entre dos hombres jóvenes, consideradas como excepciones.

(12)

Alizia

Nirekin nahi zaitut, Margari. Eta ahal dela oraintxe bertatik gainera... $\mathrm{Te} / \mathrm{La}$ quiero conmigo, Margari. Y a poder ser desde ahora mismo además...

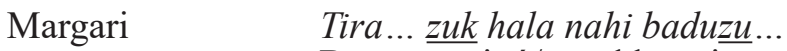

Bueno... si tú/usted lo quieres/quiere así...

Alizia Bai, Margari. Nahita ere ez dut zu bezalakorik aurkituko. Zer diozu?

Sí, Margari. Aun queriendo no voy a encontrar nadie como tú/usted. ¿Qué dices/dice?

Margari Zure aginduetara nagoela, etxekoandre!

¡Que estoy a tu/su servicio, señora!

(13)

Enriketa Erretiroko paperak iritsi zaizkit.

Me han llegado los papeles de la jubilación. 
La comparación de los pronombres de segunda persona del singular en el español peninsular y en el euskera

$\begin{array}{ll}\text { German } & \text { Ez duzu atzera egingo orduan? } \\ & \text { ¿No vas/va a echarte/echarse para atrás entonces? } \\ \text { Enriketa } & \text { Ez, erabakita dago. } \\ & \text { No, está decidido. } \\ \text { German } & \text { Baina ez dituzu } 60 \text { urte oraindik eta! } \\ & \text { ¡Pero si todavía no tienes/tiene } 60 \text { años! } \\ \text { Enriketa } & \text { Esan nizun; senarra erretiratu zait eta urte hauek aprobetxatu nahi ditugu. } \\ & \text { Te/se lo dije; mi marido se ha jubilado y queremos aprovechar estos años. } \\ \text { German } & \text { Eta zer egin behar dut zu gabe? } \\ & \text { ¿Y qué voy a hacer sin ti/usted? } \\ \text { Enriketa } & \text { Topatuko duzu beste norbait. } \\ & \text { Ya encontrarás/encontrará a alguien. } \\ \text { German } & \text { Nik zu maite zaitut, ordea. Zu bakarrik. } \\ & \text { Yo te/la quiero a ti/usted, sin embargo. Solo a ti/usted. }\end{array}$

\subsection{Comparación de los Pro2s del español y euskera}

Con los resultados expuestos en la sección anterior tanto para los Pro2s del español como los del euskera, se pasa ahora a responder a la segunda pregunta de investigación, en la que es confirmada de nuevo la predicción planteada antes de realizar el análisis: los Pro2s de ambas lenguas no son equiparables por su significado pragmático y por la existencia de un pronombre pragmáticamente no marcado en euskera. Efectivamente, es evidente que, por lo menos en los contextos analizados, los Pro2s de ambos idiomas no son equiparables, en cuanto que tú e $h i$ no tienen los mismos usos ni parecen establecer las mismas relaciones interpersonales a través de ellos; lo que también ocurre con usted y zu. Por ejemplo, ha quedado evidenciado que en español el pronombre común entre las parejas es el tú simétrico, mientras que en euskera es el uso recíproco de $z u$, normalmente considerado como pronombre formal o de respeto. Pero, ¿se trata realmente de un pronombre formal en este contexto?

Al revisar uno por uno los contextos conversacionales en los que se han analizado los Pro2s en este proyecto, se ha visto que, en el contexto familiar actual en español, los hablantes usan tú de forma recíproca, creando así relaciones interpersonales cercanas y entre iguales. No obstante, se ha observado que el caso del euskera es más complejo que el del español, haciendo imposible equiparar de forma absoluta el pronombre tú al normalmente considerado pronombre familiar $h i$ en euskera. En el único contexto familiar en el que estos Pro2s mencionados son equiparables es en las conversaciones entre hermanos, al usar hi de manera simétrica: así se crea también una relación interpersonal cercana y de iguales. En cambio, en las demás relaciones familiares — por ejemplo, solo entre mujeres o en conversaciones con personas de ambos géneros, sean de la misma generación o no- se ha visto que hay un uso recíproco de $z u$. Por tanto, lo que se evidencia es que $z u$ no se define como un pronombre formal y no es equiparable al usted: no hay ninguna razón para pensar que estos familiares y parejas tengan una relación de distancia y no de cercanía. En cambio, cuando se encuentran ejemplos en los que hay familiares de diferentes generaciones usando los Pro2s de forma asimétrica, en estos contextos $z u$ sí obtiene un significado de deferencia, distancia y respeto, que no niega un sentimiento de cariño hacia el familiar. 
La comparación de los pronombres de segunda persona del singular en el español peninsular y en el euskera

Algo similar se puede extraer de las conversaciones entre amigos en ambos idiomas. Se ha visto que en el español centro-norteño las personas que mantienen una relación de amistad emplean el pronombre tú recíprocamente, lo cual permite establecer unas relaciones interpersonales lo más cercanas e igualitarias posibles. En cambio, en euskera, el uso de los Pro2s entre amigos es más variado. Los hombres de edades parecidas usan $h i$ de forma simétrica, lo que significa que sus relaciones son cercanas, igualitarias y familiares. Entonces, ¿qué tipo de relaciones establecen las mujeres de generaciones similares, incluso los hablantes de ambos sexos, que en su caso usan el pronombre tradicionalmente considerado formal $z u$ de forma recíproca? Siguiendo las definiciones tradicionales de los Pro2s del euskera, podría suponerse que son relaciones distantes y no cercanas. Sin embargo, esta afirmación no se puede sostener en lo que respecta a este trabajo ya que se considera que sus relaciones interpersonales son iguales a las que establecen los hombres con el uso recíproco de $h i$. En consecuencia, zu no sería un pronombre formal tampoco en este ámbito conversacional, a excepción de las pocas conversaciones halladas en las que dos amigos emplearon los Pro2s de forma asimétrica.

Finalmente, en lo relativo a las conversaciones con distancia social y de poder, la situación de las dos lenguas también es diferente. Por un lado, según los estudios analizados en este proyecto, en el español centro-norteño los Pro2s se usan de forma asimétrica: estas relaciones no son entre iguales y la distancia y diferencia de poder entre ellos salta a la vista. Por su parte, en euskera, estas conversaciones están marcadas por el uso simétrico de $z u$ : no queda claro si se trata del pronombre formal y puede equipararse con usted en español o si se trata, en este contexto, del pronombre pragmáticamente no marcado.

\section{Discusión y conclusión}

Con el análisis expuesto en la sección anterior, se concluye que los Pro2s de las dos lenguas incluidas en este trabajo no se usan de forma similar o en los mismos contextos conversacionales. De hecho, se puede decir que este trabajo indica que los Pro2s del euskera están más restringidos que los del español peninsular, en cuanto a género y edad se refiere, o lo que es similar, en esta variedad del español, en la actualidad, se crean relaciones interpersonales más igualitarias que en euskera. Esto apoya afirmaciones como las de Alberdi Larizgoitia (1991), las cuales sostienen que en euskera se siguen dando muchos más casos de asimetría de pronombres en comparación con sus lenguas vecinas.

Lo que se extrae de este análisis es que el pronombre $z u$ no puede ser considerado un pronombre formal, por lo menos no en su totalidad. Aunque durante un tiempo haya podido ser considerado un pronombre formal posiblemente, por intentar equiparar el euskera a las lenguas romances vecinas - los datos del presente estudio indican que solo se podría considerar un pronombre formal en aquellos casos en los que haya un uso asimétrico de los Pro2s. En cambio, en otros contextos, se puede considerar un pronombre no marcado pragmáticamente (Amorrortu, 2003; de Rijk, 1991, 2008).

En conclusión, este trabajo inicial sugiere que los Pro2s del español centro-norteño y del euskera no son 
La comparación de los pronombres de segunda persona del singular en el español peninsular y en el euskera equivalentes en cuanto a significado pragmático, lo cual respalda sugerencias anteriores como la de de Rijk (1991), las cuales ya anunciaban que era un error considerar los Pro2s de estos idiomas como iguales, probablemente encontrando el origen de esta equivocación en la comparación del euskera con las lenguas romances vecinas (de Rijk, 1991, 2008; Zubiri \& Zubiri, 2012). Así, el presente trabajo confirma que $z u$ es un pronombre pragmáticamente no marcado e $h i$ es un pronombre familiar (Amorrortu, 2003 de Rijk, 1991, 2). Otra opción sería, tal y como se ha mencionado antes, que $z u$ pueda ser usado formalmente o de manera íntima, tal y como ocurre con el ustedeo en, por ejemplo, Costa Rica y Colombia (Calderón Campos, 2010).

Si enfocamos la perspectiva en futuros proyectos que analicen y comparen los usos de los Pro2s en español y en euskera, es obvio que una de las maneras más convenientes de ampliar el conocimiento sobre la comparación entre los Pro2s del español peninsular y del euskera sería a través del análisis de conversaciones reales y recientes en ambos idiomas para evitar las limitaciones del análisis de este estudio. Además, también sería pertinente ampliar el área de estudio y examinar el uso de los Pro2s por hablantes bilingües de español y euskera, para comprobar si estos hablantes transfieren los Pro2s de un idioma a otro. Incluso, se podría analizar si hay diferencias en el uso de los Pro2s entre los nuevos hablantes de euskera — euskaldun berriak - y los nativos de euskera —euskaldun zaharrak-. 
La comparación de los pronombres de segunda persona del singular en el español peninsular y en el euskera

\section{Referencias bibliográficas}

1. Alberdi Larizgoitia, J. (1991). Hikako tratamenduaren balore sozio-afektiboak. Fortes Linguae Vasconum, Studia et Documenta, 64, 425-442.

2. Alberdi Larizgoitia, J. (1994). Hitanoa non eta nork erabilten duen. Euskera, xxxix, 983-993.

3. Alberdi Larizgoitia, J. (1995). The Development of the Basque System of Terms of Address and the Allocutive Conjugation. En J. I. Hualde, J. A. Lakarra \& R. L. Trask (Eds.), Towards a History of the Basque Language. (pp. 275-293). Netherlands: John Benjamins Publishing Company.

4. Amorrortu, E. (2003). Basque Sociolinguistics: Language, Society and Culture. Reno, NV: Center for Basque Studies.

5. Ardila, J. (2003). (Non-deictic, Socio-expressive) T-/V-pronoun Distinction in Spanish/English Formal Locutionary Acts. Forum for Modern Language Studies, 39, 74-86.

6. Bereziartua Etxeberria, G., \& Muguruza Aseginolaza, B. (2018). Erabileraren gakoak egoera informaletan eta gazteen artean: hitanoa Azpeitiko gazteen artean. Hermes: Pentsamendu Eta Historia Aldizkaria, 60, $24-28$.

7. Blas Arroyo, J. L. (1995). Tú y usted: dos pronombres de cortesía en el español actual. Datos de una comunidad peninsular. Revista ELUA, 10, 21-44.

8. Blas Arroyo, J. L. (2005a). Los grados de la cortesía verbal: reflexiones en torno a algunas estrategias y recursos lingüísticos en el español peninsular contemporáneo. Revista Internacional de Lingüística Iberoamericana, 3(1), 9-29.

9. Blas Arroyo, J. L. (2005b). Sociolingüística del español. Desarrollos y perspectivas en el estudio de la lengua española en contexto social. Madrid: Cátedra.

10. Brown, P., \& Gilman, A. (1960). The Pronouns of Power and Solidarity. En T. A. Sebeok (Ed.), Style in Language (pp. 253-276). UK: Literary Licensing, LLC.

11. Brown, P., \& Levinson, S. C. (1978). Universals of Language Usage: Politeness Phenomena. En E. Goody (Ed.), Questions and Politeness (pp. 56-289). UK: Cambridge University Press.

12. Brown, P., \& Levinson, S. C. (1987). Politeness: Some Universals in Language Usage. Cambridge: Cambridge University Press.

13. Calderón Campos, M. (2010). Formas de tratamiento. En M. Aleza Izquierdo \& J. M. Enguita Utrilla (Eds.), La lengua española en América: normas y usos actuales (pp. 225-236). Valencia: Universitat de València.

14. Calderón Campos, M., \& Medina Morales, F. (2010). Historia y situación actual de los pronombres de tratamiento en el español peninsular. En M. Hummel, B. Kluge \& M. E. Vázquez Laslop (Eds.), Formas y fórmulas de tratamiento en el mundo hispánico (195-222). Austria: El Colegio de México, Centro de Estudios Lingüísticos y Literarios.

15. Carricaburo, N. (1997). Las fórmulas de tratamiento en el español actual. Madrid: Arco Libros.

16. De Jonge, B., \& Nieuwenhuijsen, D. (2012). Forms of Address. En J. I. Hualde, A. Olarrea \& E. O’Rourke 
La comparación de los pronombres de segunda persona del singular en el español peninsular y en el euskera (Eds.), The Handbook of Hispanic Linguistics (pp. 247-262). Malden, MA: Wiley-Blackwell.

17. De Rijk, R. P. G. (1991). Familiarity or Solidarity: The Pronoun hi in Basque. Revista Internacional de los Estudios Vascos, 36(2), 373-378.

18. De Rijk, R. P. G. (2008). Standard Basque: A Progressive Grammar (Vol. 1). Cambridge, MA: The MIT Press. 19. Echeverria, B. (2003). Language Ideologies and Practices in (en)gendering the Basque Nation. Language in Society, 32, 383-413.

20. Esparza Celorrio, S. (2006). Influencias del vasco en el castellano. Journal of Inquiry and Research, 84, $125-$ 138.

21. Euskaltzaindia. (1991). Euskal Gramatika: Lehen Urratsak-I. Bilbo: Euskaltzaindia.

22. Euskaltzaindia. (2002). Euskal Gramatika Laburra: Perpaus Bakuna. Bilbo: Euskaltzaindia.

23. Euskaltzaindia. (2008). Lexikoaren Behatokia. http://lexikoarenbehatokia.euskaltzaindia.eus

24. Fernández-Mallat, V. (2020). Forms of Address in Interaction: Evidence from Chilean Spanish. Journal of Pragmatics, 161, 95-106.

25. Fernández Ulloa, T. (2006). Influencias morfosintácticas de la lengua vasca en el castellano actual. Oihenart, 21, 73-99.

26. Lambert, W. E., \& Tucker, G. R. (1976). Tu, vous, usted: A Social-psychological Study of Address Patterns. Rowley, MA: Newbury House Publishers, Inc.

27. Larramendi, M. (1728). De la antigüedad y universalidad del bascuenze en España. Salamanca: Eugenio García de Honorato.

28. Larramendi, M. (1729). El impossible vencido: Arte de la lengua bascongada. Salamanca: Antonio Joseph Villagordo Alcaraz.

29. León-Castro Gómez, M. (2014). Sobre el empleo de la segunda persona del singular como mecanismos de indefinición referencial en el habla culta. Diferencias entre las formas tú/vos y usted. Lingüistica y Literatura, 65, 37-63.

30. Morgan, T. A., \& Schwenter, S. A. (2016). Vosotros, Ustedes, and the Myth of the Symmetrical Castilian Pronoun System. En A. Cuza, L. Czerwionka \& D. J. Olson (Eds.), Inquiries in Hispanic Linguistics. From Theory to Empirical Evidence (pp. 263-279). Amsterdam: Benjamins.

31. Nuzzo, E. (2015). Comparing Textbooks and TV Series as Sources of Pragmatic Input for Learners of Italian as a Second Language: The Case of Compliments and Invitations. En S. Gesuato, W. Cheng \& F. Bianchi (Eds.), Teaching Learning and Investigating Pragmatics: Principles, Methods and Practices (pp. 85-107). Cambridge: Cambridge Scholars Publishing.

32. Pedroviejo Esteruelas, J. M. (2006). Un estudio sociolingüístico. Sistemas de tratamiento de la juventud de Valladolid. Revista de Estudios Filológicos, 11.

33. Quaglio, P. (2009). Television Dialogue. The Sitcom Friends vs. Natural Conversation. Amsterdam: Benjamins. 34. RAE \& ASALE (Real Academia Española y Asociación de Academias de la Lengua Española). (2009). Nueva 
La comparación de los pronombres de segunda persona del singular en el español peninsular y en el euskera gramática de la lengua española, vols. I y II. Madrid: Espasa.

35. Saltarelli, M. (1988). Basque. London: Croom Helm.

36. Sampedro Mella, M. (2016). Las formas de tratamiento «tú y usted» en el español centro-norte peninsular. Estudio sociolingüistico. Salamanca: Ediciones Universidad de Salamanca.

37. Sanromán Vilas, B. (2010). Sociolingüística de los pronombres de segunda persona: estudio contrastivo entre dos ciudades españolas. Neuphilologische Mitteillungen, 111(4), 479-502.

38. Serrano, M. J. (2017). Going Beyond Address forms: Variation and Style in the Use of the Second-person Pronouns tú and usted. Pragmatics, 27, 87-114.

39. Trask, R. L. (1997). The History of Basque. New York, NY: Routledge.

40. Trask, R. L. (2003). The Noun Phrase: Nouns, Determiners and Modifiers; Pronouns and Names. En J. I. Hualde \& J. Ortiz de Urbina (Eds.), A Grammar of Basque (pp. 113-170). Berlin, Boston: De Gruyter Mouton. 41. Urrutia Cárdenas, H. (2006). El bilingüismo en la CAV (Comunidad Autónoma Vasca): aspectos lingüísticos y educativos. Oihenart, 21, 481-520.

42. Wolpert, M., Mancini, S., \& Caffarra, S. (2017). Addressee Identity and Morphosyntactic Processing in Basque Allocutive Agreement. Frontiers in Psychology, 8, 1-11.

43. Zubiri, I., \& Zubiri, E. (2012). Euskal gramatika osoa. Bilbo: G. Z. Printek. 